\title{
Medical Migration: a review on the licensing process for International Medical Graduates in Australia and other destinations
}

\author{
Sharafat Malek', Prof. Dr. Md. Humayun Kabir Talukder ${ }^{2}$
}

\begin{abstract}
Movement of health care professionals, nationally or internationally, has now become a common trend worldwide. International recruitment of efficient physicians is an ongoing process for years although some studies have identified this culture as an issue..$^{10-11}$

Waves of migration to popularly Australia under 'Skilled Migration' and other categories started in Bangladesh in early 1970, which have been ongoing since then. Among over thirty thousands of such migrants living in the popularly Australian States $^{2}$; the medical graduates from Bangladesh are identified through their associations/forum made in each State as well as from the data on their participation in the re-accreditation examinations. ${ }^{3-4,7-8}$

A lack of pre-migration awareness on social and academic barriers in the host country has been found far more common in the Australian International Medical Graduates' (IMGs) studies published before 2004 ${ }^{5}$. Poor knowledge on the hurdles may affect IMGs' post-migration coping or adjustment process. Fortunately, internet facilities are widely available so, modern IMGs no more need to rely on information from relatives, friends or high commission/embassy people. Yet, full access to career and job related journals could still be out of reach for many IMGs. Updated clear knowledge around licenselegislation at the destination would help IMGs gaining smoother transition whilst preparing to build the same career, albeit in a different system.

This review article at first presents the background behind strict regulations on permitting the IMGs to practise in major destinations. It then progresses with reviewing these regulations in the developed countries including Australia. Following that a detailed summary has been made on the Australian regulations. Available literature ${ }^{6-8}$ demonstrates a large discrepancy between IMGs' success rates in the knowledge and practical part of the licensing (Australian Medical Council) process (i.e. $80 \%$ vs. $42 \%$ in case of Bangladeshi-IMGs). Therefore, this paper has properly discussed the nature and structure of the practical (AMC-Clinical) examination incorporating examples. Useful web-links on Australian IMGs' accreditation preparation, permanent migration and finding medical jobs have been provided at relevant sections. Finally, a recommendation has been made to teach $3^{\text {rd }}$-year medical students on this important area under the 'Community Medicine' curriculum in Bangladesh.
\end{abstract}

\section{Background}

The international movement of doctors from one country to another has a long history and continues to be common worldwide. To label this group, the terms 'Foreign medical graduates (FMG)', 'Overseas-trained doctors (OTDs)' or more recently 'International Medical Graduates (IMGs)' are being used. Such terms indicate to medical graduates who have completed their primary medical degrees in a country outside of their post-migration host countries. In most cases, the members of this group are not permitted to see or treat patients in their welcoming society straight away. ${ }^{9}$

The published number on the IMGs' inclusion into health care system of their host countries varies widely. In the USA,

${ }^{1}$ Researcher, University of Sydney, Australia

${ }^{2}$ Professor, Curriculum Development \& Evaluation, Centre for Medical Education (CME), Mohakhali, Dhaka.

Address of correspondence: Dr. Sharafat Malek

Researcher, University of Sydney, Australia

Emal: sharafat.malek@gmail.com one in five of its physicians received their medical qualifications in another country, either a developed or a developing nation. ${ }^{10}$ On the other hand; IMGs remain only 3 percent of the physician workforce in France, 5 percent in Germany and 1 percent in Japan. In addition, only 17.8 percent of IMGs in Switzerland and 12.7 percent in Sweden and Norway come from outside Europe.

Until the "Melbourne Medical School" was founded in 1862 and its first doctors graduated in 1867, all western doctors practicing in Australia were trained overseas and until federation in 1901, most doctors who practiced in Australia were overseas-trained doctors. Indeed until well into the $20^{\text {th }}$ century, many leading medical practitioners and administrators in Australia were overseas graduates..$^{12-13}$ The Australian literature identifies them as coming from a diverse variety of cultures and often struggle to adapt to living and working in a different socio-cultural-linguistic environment. ${ }^{14-15}$ The 2008 workforce data showed that $31 \%$ of general practitioners (GP) in Australia are IMGs. This percentage of GP-IMGs is greater in rural and remote areas $(37 \%)$ than in metropolitan areas $(28 \%))^{16}$

Bangladesh Journal of Medical Education 2018;9(1):26-34. (C) 2018 Malek et al., publisher and licensee Association for Medical Education. This is an Open Access article which permits unrestricted non-commercial use, provided the original work is properly cited. 
Table 1: A review of IMGs' license process in Australia and New Zealand

\begin{tabular}{|c|c|}
\hline Countries & The medical license (accreditation) process \\
\hline Australia & $\begin{array}{l}\text { Primary source verification of the final medical degree by ECFMG (In some major states but not all yet)? An English } \\
\text { language test for foreign nationals (English } 2^{\text {nd }} \text { language) ? AMC part } 1 \text { (computerized MCQ)/ / / exemption granted } \\
\text { by AMC for competent authority countries] ? AMC part } 2 \text { (Clinical-OSCE)/WBA for exempted countries ? 1yr } \\
\text { supervised internship? Prevocational general registration? further HMO job? RACGP approval + PESCI interview } \\
\text { pass? GP. } \\
\text { Prevocational training leads to vocational training that ends with a fellowship exam on chosen specialty? i.e. } \\
\text { FRACGP. } \\
\text { After obtaining fellowship (vocational registration), one needs to take further specific training for at least three years } \\
\text { (depending on the availability of the positions) to become a specialist? i.e. FRACP. } \\
\text { Permanent resident IMGs get work restriction for first ten years that allows them to practice in 'Non-metropolitan } \\
\text { areas' only (10yr moratorium). Temporary resident IMGs get their registrations to work in workforce shortage areas } \\
\text { only (Hospital/GP). } \\
\text { Skilled IMGs may be registered conditionally in specific categories and be employed before completing the whole } \\
\text { AMC process. } \\
\text { Under current policy, holding NZ-MBBS or New Zealand citizen IMGs bearing standard/fellowship registrations } \\
\text { from there, are eligible for gaining automatic registration (Trans Tasman agreement) in Australia. } \\
\text { Special category of conditional Aust. registration is also possible for skilled academic/health-researchers and eminent } \\
\text { medical teachers. } \\
\text { Information on any recent change in standard and/or alternative pathways for registration is available from the AMC } \\
\text { (http://www.amc.org.au) \& Doctor Connect (http://www.doctorconnect.gov.au) website. }\end{array}$ \\
\hline $\begin{array}{l}\text { New } \\
\text { Zealand }\end{array}$ & $\begin{array}{l}\text { A valid (2yrs) English language test score for foreign nationals (English } 2^{\text {nd }} \text { language) ? UK-PLAB/AMC-1/USMLE- } \\
1 \& 2 \text { passed ? NZREX Clinical pass (5-yrs validity)? 1yr supervised internship? General registration. } \\
\text { Australian \& UK local graduates do not need to undergo any examination or assessment process and directly enter } \\
\text { supervised internship. } \\
\text { Temporary supervised registration (for 3yrs max.) is also possible for IMG-visitors. } \\
\text { Recent NZ policy allows doctors in certain circumstances to move from temporary to probationary registration } \\
\text { without examination or assessment. } \\
\text { Information on any recent change in NZ-registration is available from: https://www.mcnz.org.nz/get- } \\
\text { registered/registration-exam-nzrex-clinical/ }\end{array}$ \\
\hline
\end{tabular}

The IMG-accreditation-requirements in other countries are similarly strict or even stricter. A review of IMGs' re-qualification requirements (standard, not the specialist pathway) in other developed countries has been made in Table 2 . $^{11,20,24-25}$ 
Table 2: A review of IMGs?license process in other developed countries

\begin{tabular}{|c|c|}
\hline Countries & The license (accreditation) process \\
\hline The United States & $\begin{array}{l}\text { Primary source verification of the final medical degree by ECFMG? An English language test for foreign nationals } \\
\text { (English 2nd language)? USMLE step } 1,2 \& 3 \text { ? 3yr accredited residency training program. Special considerations } \\
\text { are in place but only for academic health researchers and eminent medical teachers. } \\
\text { Recent updates are at: http://www.usmle.org \& http://www.ecfmg.org }\end{array}$ \\
\hline Canada & $\begin{array}{l}\text { Forms of licensing vary slightly by province in Canada. Standard requirement has been set by LMCC which all } \\
\text { provinces have to follow. Requirements in Ontario province are more aligned with requirements in the US, the UK, } \\
\text { NZ and Australia. Two main types of licenses: full and provisional. Provisional licenses allow IMGs to enter } \\
\text { directly into practice, despite not meeting all the requirements. } \\
\text { An MCC acceptable medical degree equivalent to local MD degree? A French or English language test for non- } \\
\text { native speakers? A pass on the MCCEE written evaluation exam on medical knowledge from inside or overseas } \\
\text { locations? } 2 \text { to 5yr accredited residency training program depending on the chosen specialties by applying through } \\
\text { Clearinghouse? MCCQE part } 1 \& 2 \text { ? Supervised license from LMCC? Fellowship exam in chosen specialty? } \\
\text { Ontario Registration. } \\
\text { Recent updates are at: http://www.mcc.ca, http://www.aipso.ca \& http://www.mun.ca/harriscentre/IMG- } \\
\text { Atlantic_Metropolis-FINAL.pdf }\end{array}$ \\
\hline United Kingdom & $\begin{array}{l}\text { A GMC accredited medical degree? An English language test for foreign nationals (English 2nd language) ? PLAB } \\
\text { part } 1 \text { \& } 2 \text {. } \\
\text { Since March 2006, every medical job is being filled by manpower on following priority: UK-graduates? EU- } \\
\text { graduates? others (IMGs). } \\
\text { ODTS? The aim of this scheme is for temporary OTDs to return to their country of origin on completion of specialist } \\
\text { training in the UK. } \\
\text { Recent updates are available at: http://www.gmc-uk.org/doctors/index.asp (accessed on 30.1.17) }\end{array}$ \\
\hline Ireland & $\begin{array}{l}\text { There is an oversupply of Irish doctors for posts in Ireland. Non-EU nationals generally work in smaller hospitals all } \\
\text { over the country ( } 879 \text { were registered in 1994). Temporary registration with the Medical Council last for a } \\
\text { maximum period of five years. A full-time work permit and the letter of employment are essential before a visa is } \\
\text { considered to the applicant. EU nationals are exempted from these requirements. } 26\end{array}$ \\
\hline Israel & $\begin{array}{l}\text { Israel has surplus of local graduates per population. Yet it receives an unprecedented wave of doctor immigration } \\
\text { each year, mainly from the former Soviet Union or Europe. Both local and foreign graduates have to pass the } \\
\text { National Licensing Examinations (NLE) to be able to practice. The license exam format is very close to that of final } \\
\text { year MD examination. The official spoken language in medical practices is Hebrew. There is Government funded } \\
\text { training program for IMGs to prepare for the NLEs however, competition for its access is very high. } 27\end{array}$ \\
\hline Scandinavia & $\begin{array}{l}\text { In general, all degrees, license status and positions acquired in EU countries are reciprocally accepted and } \\
\text { acknowledged amongst member countries. } \\
\text { If an IMG graduated from a non-EU medical school then medical registration is only possible if the candidate holds } \\
\text { 'Permanent Residence' status of that country and his/her medical diploma is acceptable by their license authority. If } \\
\text { graduation is accepted, then to pass a local language test? passing a medical exam to qualify as pre-registration } \\
\text { doctors (AT) which enables him/her to work as Junior House Officers in hospitals. } \\
\text { The AT period ( } 21 \text { months) consists of four major specialties terms (each four month long) and other specialties of } \\
\text { interest in the remaining period? to pass an exam at the end of the AT period? Full registration (enables one to } \\
\text { perform locum work up to one year in many supervised posts or to undertake clinical training in a chosen specialty). } \\
\text { Specialist training program (ST) lasts for five years and then one can apply for a 'Consultant' position.28 } \\
\text { Recent updates are available at (accessed on 30.1.17): http://www.saco.se/en/omstart/swedish-educational- } \\
\text { system/choose-your-education/doctorphysician/ }\end{array}$ \\
\hline
\end{tabular}

One literature suggests that a decade ago in 2005, there had been sufficient locally-trained graduates in the UK, Eire and Scandinavia for their own workforce.29 Another report30 has alerted that doctor-movement could be an expensive process; according to Dr Shiv Pande (Chairman of the British International Doctors Association in 2006) in the report:

Bangladesh Journal of Medical Education 2018;9(1):26-34. 


\begin{abstract}
"Before overseas doctors can work they have often spent hundreds of pounds on visas, exams, and registration, and this is often money that they just haven't got. Some doctors end up in huge amounts of debt trying to get on the work treadmill. Some have to live in squalid conditions while trying to get work"
\end{abstract}

So, a pre-informed and well-organized preparation is necessary that would ease the process.

\section{The Regulation of IMGs in Australia}

Australian medical practice regulations were formalized more than two decades before the UK in 1859. The first regulatory board was formed in Australia ${ }^{31}$ by establishment of the 'Medical Council of Tasmania' in 1837. However, it was not until the late 1970s that exams for IMGs were introduced. The level of control on IMGs' inclusion into medical workforce has gradually increased. . $^{13-14,32}$

Australia is experiencing a chronic shortage of Australiantrained doctors available to work in certain disciplines, for example General Practice, Psychiatry and Emergency Medicine and also in certain regions and places, especially rural and remote Australia. The distribution of general practitioners is unequal with capital cities having access to more doctors than rural areas. ${ }^{33}$

A current major workforce focus is how to increase the number of primary care physicians (GPs) working in underserved areas. Since 2000, Federal Governments have undertaken initiatives to increase medical student places, created new medical schools in rural and regional locations and funded shorter graduate-entry medical courses. ${ }^{34} \mathrm{~A}$ range of beneficial initiatives for IMGs wanting to relocate and practice in rural locations were introduced. The goal is to reach nationwide self-sufficiency in number and distribution of doctors by $2025 .^{6}$

While waiting for the number of Australian graduates to increase, one ready solution to workforce shortages is hiring IMGs on temporary visas. ${ }^{6}{ }^{16}$ However, to practice in Australia, IMGs need to gain accreditation and this process is complex and has changed over time.

\section{The Medical Licensing pathway for IMGs:}

National examinations for IMGs were introduced to Australia in 1978. These examinations have been run and regulated by the Australian Medical Council (AMC) since 1990. The AMC is an independent national body in Australia. Its purpose and responsibility is to ensure the standards of medical education and training and to assess the health professionals trained locally or abroad in order to protect and maintain the optimum health of people living in Australia. Since 1992, the IMGs' license to practice had been consistent and restrictive across states and territories. In general it is achievable only by satisfactorily completing the examination requirements of the AMC. ${ }^{35}$ According to Professor Gordon G. Page ${ }^{36}$ :
The examinations of the AMC are developed to assess competence at the level of a graduate from an Australian medical school, and assess competence relative to the requirements of safe, effective medical practice and health care in Australia.

The AMC offers two registration pathways; the 'Standard pathway' for general registration, and the 'Specialist pathway' for fellowship recognition. For IMG-specialists, the $\mathrm{AMC}$ coordinates the qualification recognition process (through its specialist pathway) however; the actual assessment of qualifications (i.e. fellowship, membership) and relevant accreditation exams are carried out by the relevant specialist medical colleges. For example, the Royal Australian College of General Practitioners (RACGP) assesses the overseas general practitioner (GP) qualification of an applicant and his/her relevant training obtained in the area. The RACGP also organizes/controls the pre-vocational and vocational general practice training of IMGs and undertakes GP fellowship exams. The information on the specialist qualification recognition of IMGs is available from the AMC website link: http:// www.amc.org.au/ accreditation/recognition-changes - accessed on 29/1/17]. Any additional information surrounding the overseas GPfellowship recognition process is available from the RACGP and the AHPRA website. ${ }^{37-38}$

The components of the AMC Standard Pathway are:

\section{Primary medical degree verification:}

Not all primary-medical-degree providing institutions are recognized by the AMC. So, IMGs are advised to check their institution's eligibility before applying for an AMC assessment. The updated list on eligible schools for the purpose is available from the AMC website. ${ }^{56}$

The AMC assessment starts with the verification of an applicant's primary medical qualification. This preliminary verification process of primary medical degree often makes some unknown delay as has been reported by some newly arrived Bangladeshi doctors (Personal communication via BDFV). The AMC has listed (2013-14) the worldwide medical colleges that are slow to respond to this verification request (Source: PDF file at bottom page of http:// www.amc.org.au/assessment/psv - accessed on 30.1.17). This verification process was implemented by the AMC on $1^{\text {st }}$ January 2006. Since then, the AMC checks the credentials of both general and specialist stream applicants by sending those documents to an expert American organization called 'Educational Commission for Foreign Medical Graduates (ECFMG)'. This body checks the documents with the confirming institution. More recently, all applications that are received from 1 Oct, 2015 have to go through ECFMG's new system called 'Electronic Portfolio of International Credentials (EPIC)' for verification of IMGs' medical credential. All these are done at the candidate' expense and if this verification cannot be confirmed; the AMC would neither allow scheduling exams nor issue final certificate for obtaining a medical registration (http://www.amc.org.au/ assessment/psv - Accessed on 26.1.17).

Bangladesh Journal of Medical Education 2018;9(1):26-34. 
2. The English language tests for non-native speakers:

The literature has isolated 'linguistic problem' as the first barrier against progress of immigrant doctors ('Englishsecond-language' speakers) towards the medical licensing exams in Israel. ${ }^{27}$ Moreover, research on foreign students in the United States ${ }^{39}$ and in Australia ${ }^{40}$ found that there is a positive correlation between students' English language ability and both their academic successes (in any discipline) and social adjustment. These researches also indicated that the academic achievement of foreign students affects (and are affected by) their attitudes and adjustment.

Before 2007, to get registered with the AMC, an IMG firstly has to pass one of the recommended English language tests such as: International English Language Testing System (IELTS) - to score band '7' in each component (Reading, writing, listening and speaking) or Occupational English Test (OET) - to score minimum level ' $\mathrm{B}$ ' in above components and to pass all components together. Currently, all English test scores have a two year period of validity since its pass date. ${ }^{98}$ The worldwide (incl. Bangladesh) list of 2017 IELTS and OET test dates and centers are available at (Accessed on 26.1.17):

1. http://www.britishcouncil.org.bd/en/exam/ielts/datesfees-locations

2. https://www.occupationalenglishtest.org/testinformation/test-dates-locations/

The AMC exams for general (unconditional) registration comprises: a computer-based Multiple Choice Questions (MCQ) exam and, a practical (Clinical) exam. ${ }^{9}$

\section{The AMC-MCQ examination:}

The MCQ questions focus on medical knowledge and its application to understanding and interpretation of data and solving health problems. The questions cover all major disciplines and sub-disciplines of medicine. The MCQ exam consists of 150 questions to be completed in a three-and-ahalf-hour session. The question format is of Type-A (one correct response from five choices). Since 2011, the MCQ exam format has been replaced by a new examination format called 'Computer Adaptive Testing (CAT)'. In new system, the MCQs will randomly appear from the item pool in computer according to the candidate's ability level [Source: http://www.amc.org.au/assessment/mcq-exam accessed on 29.1.17].

\section{The AMC-Clinical examination:}

The Clinical exam tests the skills and proficiency of historytaking, physical examination, diagnosis, investigation, treatment and communication via a specific type of clinical examination called the 'objective structured clinical examination (OSCE)'. ${ }^{41}$ The current multi-station 'AMCOSCE' checks candidates' consultation and appropriate referral techniques. This exam is often a hurdle for many IMGs. On $7^{\text {th }}$ December 2007, the then AMC President commented on launching an AMC's publication that "Close to $40 \%$ IMGs who pass the initial AMC MCQ examination, fail the subsequent clinical examination". ${ }^{42}$
The age of candidates could be a factor with license exams' preparation and outcome. Hawthorne ${ }^{6}$ commented from her observation on the workforce data that "From 2004-10, 57\% of IMGs aged 21-30 years passed the multiple choice question examination on their first attempt, compared with $46 \%$ aged $41-50$ years and $31 \%$ aged over 50 . Similar trends were evident in the clinical examination". Could we say, earlier the migration decision- better for IMGs' career progress in their new country?

Inspired by above statistics and to better understand the format and components of the Clinical exam, I attended a seminar on 'AMC-OSCEs' organized by a reputed bridgingcourse provider in Melbourne. The invited speaker (Professor) there had conducted research with a group of AMC clinical exam candidates. The research looked at candidates':

a. Lack of appropriate clinical reasoning strategy towards generating a diagnosis; and

b. The difficulties experienced acting at an expected standard in the 'role play' scenarios within the oral examination process (OSCE).

According to the presenter, the OSCE is a key oral examination format in medical education that also is being used at the AMC clinical exam. Here, typically a candidate is required to convey his/her medical knowledge and demonstrate clinical skills via scenarios. Interaction in the scenario can be with real or simulated patients (actors) at several short stations of 8-15 minute duration. For the AMC clinical exam, each of the $\mathbf{1 6}$ stations is 10 minute (two minute for reading the scenario and next eight minute for the exam) long. Ideally, the major components in a standardized checklist are history-taking, focused physical examination, promptness, communication, attitude and empathy. Assessment of candidates typically is done through marking on a 0 to 7 point scale for each of the above items and getting at least four in each of those components makes a 'pass' for that particular station. The presenter reported that each scenario has got a 'critical error' point which is significantly associated with 'patient safety' values or 'medico-legal' issues. Naturally, giving the wrong answer at this point leads to a failure. Finally, passing 12 or more out of the 16 stations is needed for a complete pass and those, who pass between 10 or 11 stations can return to take a shorter version of the exam (called 'Re-test') offered at a lesser cost. The Re-test exam comprises of eight stations out of which, minimum six are needed to be passed.

The presenter demonstrated two such scenarios/stations and statistics on IMGs' performance in those. The identified associated problems had been also explained. The scenarios are presented below:

\section{Scenario-1:}

Marion, a 23-year-old lady has come to see you (GP) with her partner. She suffers from a longstanding and recurrent genital herpes of low grade almost asymptomatic. Her partner plans to go overseas for a long period for a business trip.

Bangladesh Journal of Medical Education 2018;9(1):26-34. 
Both of them don't have any other sexually transmitted or other infections. Marion's reasons for visiting you today are:

- Task-1: She wants to become pregnant stopping her contraceptive pill and is seeking your advice on this.

- Task-2: She wants to know about the effects and management of herpes during pregnancy.

- Task-3: She wants to know about the effects of herpes on the baby during or after delivery. Seeks your advice on appropriate method of delivery in her case.

Critical error: As she has very low symptoms, pregnancy can go ahead perhaps using a prophylactic antiviral drug during the last trimester of pregnancy. ${ }^{43}$ She needs to be counselled on undergoing caesarean section aimed at avoiding the risk of vaginal transmission of herpes to her baby. The exam candidate is not to counsel against pregnancy.

\section{Scenario-2:}

A 65-year-old man came to emergency department (ED) with complaints of alternate bowel habit (frequent constipation followed by diarrhoea in same day) and occasional passing of blood during bowel clearance. Following investigation it was found to be cancer affecting his left lower gut extended up to the terminal passage (anorectal part). You are an ED doctor working on that day. You need to:

- Task-1: Break this bad news (diagnosis) to the patient.

- Task-2: Counsel him to get the affected part operated on as early as possible. Briefly explain the procedure to him.

- Task-3: Show and explain to him how to use and maintain a 'Colostomy bag' following the operation. ${ }^{44}$

Critical error: To show empathy and to be careful about attitude and body language. Need to explain the tasks to him in layman terms. Not to use medical jargon during the conversation with the patient.

According to the presenter along with a regular AMC clinical examiner; those two scenarios had been carefully selected for the seminar-discussion because most 'English as a second language' IMGs, especially who undertook primary medical training from non-western medical schools, cannot avoid the critical errors associated with the above scenarios. The Professors discussed some reasons:

- Lack of medical knowledge and/or training (patient exposure) or inability to reproduce the correct knowledge accurately at the OSCE stations.

- Some diseases or conditions may not be so prominent in their home countries.

- Cultural gap in interacting/dealing with certain patients.

- Linguistic gap in interacting/dealing with patients.

Finally, the presenter commented that whatever the reasons for candidates' failure in this type of scenarios; it is vital to ensure "patient's comfort \& safety", so, there should/would be no compromise in the exam's marking process.
The critical error in first scenario reflects important Australian cultural notions of freedom and rights. It is the kind of cultural norm that IMGs from different cultures approaching clinical exams should have proper training on. The second critical error invites a difficult question - should every doctor from every country be able to efficiently perform this task? The answer is clearly 'yes' considering the literature reviewed ${ }^{45-47}$ about the issues surrounding the impact of communication skills on patient outcomes however, neither of these scenarios would be problematic if IMGs had achieved formal training about the nature of clinical practice in Australia.

\section{The Bridging (Preparatory) courses in Australia:}

While the AMC-OSCE checks candidates' consultation and appropriate referral techniques; unfortunately, even IMGs who work as hospital doctors in Australia would have little day to day exposure to this kind of general practice or family medicine based practice. Education theory strongly supports teaching on examination content and undertaking formative assessments on candidates through a relevant training programme. One NZ-literature suggested: "IMGs who do undertake effective bridging courses have higher pass rates". A list on contacts of the bridging course providers in Australia is available at the AMC website: http://www.amc.org.au/ about/contacts/bridging-course-providers (accessed on 27.1.17). Such courses as well prepare candidates for the registration-interviews taken by AHPRA $^{38}$ for example, on PESCI. ${ }^{52}$ Basic and advanced 'skill-upgrade' courses are also offered some of which are mandatory for IMGs to attend if to obtain or maintain medical registrations.

\section{The AMC publications for study-guidance:}

The AMC has published three textbooks ${ }^{36,42,49-50}$ to guide IMGs with all parts of the exam process. These can be purchased through the AMC website. The AMC claims that these books are sufficiently rich in information in the medical knowledge and clinical scenarios and that they use previously used exam material. The AMC website has warned that the reproduction, storage or transmission of any part of their exam material is against Australian law and a breach of that law will incur a large monetary penalty up to permanent termination of candidature. ${ }^{51}$ However, the argument could arise - i) Are the AMC textbook materials just a guide or do they offer sufficient study materials to facilitate the passing of exams? ii) Should AMC run its own preparatory course/s for IMGs?

\section{The General Registration and Permanent Immigration:}

Successful completion of both parts of the AMC exams and taking up to one year (if un-exempted) of supervised hospital training following that will provide an IMG with an AMC certificate which can lead to achieving his/her general registration. Considering legislation process as historically a rapidly changing field; it is recommended that update on the recent variations to the AMC pathways for IMGs are regularly 
checked from visiting this link: http://www.amc.org.au/ assessment/pathways (accessed on 30.1.17).

With general (unconditional) registration, an IMG is eligible to claim his/her 'Permanent Resident' visa by applying through the Aust. Immigration website. This is also possible for the IMG-specialists who have gained 'Conditional Specialist Registration' recognition through the relevant specialist medical colleges. ${ }^{53}$ For current other opportunities for IMGs to migrate permanently under the "Skilled migration" scheme; the "Skilled Occupation List" which is available under "Occupation Ceiling" tab at following link, needs to be visited regularly: http://www.border.gov.au/ Trav/Work/Skil (Accessed on 24.01.17).

\section{Some lucky IMGs (CA pathway and WBA system):}

In addition to current non-specialist assessment pathways, the recent 'Competent Authority (CA) pathway' exempts some candidates from taking the standard AMC examinations (MCQ and Clinical) provided their primary medical training was obtained from one of the AMC preapproved medical colleges in specific countries. These countries are: United Kingdom (UK), Canada, United States of America (USA), New Zealand and Ireland. If the AMC grants an exemption ('advanced standing'), such candidates need to at first secure a job offer in order to complete an approved period of supervised training in the Australian health system. While undertaking training, they will formally go through a workplace-based performance assessment system under the assigned supervisors. Since July of 2010, 'Workplace-based assessment (WBA)' system has been working to assess the specific and overall performance of working $\mathrm{CA} / \mathrm{mcq}$-passed IMGs at some accredited public hospitals listed in the AMC website: (http://www.amc.org.au/ assessment/pathways/standard/wba accessed on 26.01.17).

Following completion of WBA-requirements, they may be eligible to receive an AMC certificate and be granted general (full) registration to be able to work unsupervised. ${ }^{54}$

A range of 'workplace-based performance assessment' methods are currently on trial. This includes a 'Mini-CEX (mini clinical evaluation exercise)' system that involves direct observation and rating (of various skills on wellestablished scales) of a trainee in a clinical scenario followed by the provision of immediate feedback. ${ }^{16,57}$

\section{Where to search for vacant medical jobs:}

A 'Nationally Consistent Registration' system for all IMGs was reported ${ }^{16}$ to be effective from $1^{\text {st }}$ July $2010^{57}$. This process was targeted to be used for the purpose of screening, assessment and supervision requirements of IMGs who will apply for a medical (hospital) job. The process would assess the level of patient-safety (means whether an IMG has sufficient expertise to safely treat the patient) for all unsupervised scenario in the advertised positions. An applicant can satisfy this patient-safety argument by offering his/her medical qualifications and performed job experiences against the position that $\mathrm{s} / \mathrm{he}$ has applied for. ${ }^{16}$

For current GP/Specialist/Medical Officer jobs-on-offer in the advertised positions ["Districts of workforce shortages (DWS)" or "Area of Need (AON) vacancies"]; it is highly recommended that interested IMGs regularly visit the 'Doctor Connect' website (www.doctorconnect.gov.au) where links to all source of information on the licensing process, registration, visas and current vacancies is available. Outside typical hospital and gp settings, there are few other sectors where both conditional and fully-qualified doctors are needed i.e. 'National Home Doctor Service', 'Sports Events Doctors', and 'Medical Writer'. For the authorized users, the following journals are also worthy to browse for current job listings: a) Medical Journal of Australia (MJA) and b) Australian Family Physician (AFP).

\section{Conclusion}

This paper has provided up-to-date detailed information around licensing requirements for IMGs in popular destinations. It is now clear that in a new society, migratedIMGs may need an adaptive period to successfully integrate into the community, need to learn simultaneously to be a citizen as well as a doctor. They are adult learners with various commitments; therefore might experience learning difficulties due to migration experiences. Information given here would expect them to decide early and prepare adequately for the migration. At the same time, Bangladesh medical curriculum could consider including 'Medical Migration' as a module in its 'Community Medicine' block to benefit students with earlier orientation.

\section{Acknowledgement:}

I thank Monash University for supporting my $\mathrm{PhD}$ study with full scholarship. I am also grateful to the RACGP that provided access to the study-cohort and necessary support for my PhD across candidature. My co-author Prof. Dr Md H K Talukder (CME, Dhaka) has reviewed the final manuscript and delivered required suggestions and amendments. I highly appreciate for his valuable time and inspiring editorial support that has made this paper reaching the audience in a better readable format.

\section{References:}

1. ECCV. Information on history of Bangladeshi migrants' arrival in Australia. Melbourne: [Ethnic Community's Council of Victoria]; online [cited 2017 Jan 25]; Available from: http://www.eccv.org.au/contact.

2. Wikipedia. Information on number of Bangladeshi migrants in Australia. online [cited 2017 Jan 25]; Available from: https://en.wikipedia.org/wiki/ Bangladeshi_Australians.

3. BDFV. Bangladeshi Doctors' Forum in Victoria. online [cited 2009 Aug 16]; Available from: www. Bddoctorsvic.weebly.com. 
4. BAMSSA. Bangladesh Medical Society of South Australia. online [cited 2017 Jan 24]; Available from: http://www.bamssa.com.au.

5. Kidd M, Braun F. Problems encountered by Overseas Trained Doctors Migrating to Australia. Report. Melbourne: Monash University 1992.

6. Hawthorne L. International medical migration: what is the future for Australia? . MJA Open. [Review paper]. 2012;1(Suppl 3):18-21.

7. AMC. Annual Report. Kingston, ACT: Australian Medical Council Inc.2002.

8. AMC. Annual Report. Kingston, ACT: Australian Medical Council Inc.2003.

9. AMC. Assessment Pathways for IMGs' Registration. Australian Medical Council; online [cited 2017 Jan 27]; Available from: http://www.amc.org.au/assessment/ pathways.

10. Miller EA, Laugesen M, Lee SYD, Mick SS. Emigration of New Zealand and Australian physicians to the United States and the international flow of medical personnel. Health Policy. 1998;43(3):253-70.

11. Mullan F. The Metrics of the Physician Brain Drain. NEJM. 2005;353(17):1810-18.

12. Due S. John Day: a colonial medical life. Journal of Medical Biography. 1995;3:99-104.

13. Kunz FE. The intruders: refugee doctors in Australia. Canberra: Australian National University Press; 1975.

14. Birrell B. Hunger Strikes and the Accreditation of Overseas Trained Doctors in Australia. People and Place. 1997;5(4):1-7.

15. Van Der Weyden BM, Chew M. Arriving in Australia: overseas-trained doctors. MJA. 2004;181(11/12):633-4.

16. McLean R, Bennett J. Nationally consistent assessment of international medical graduates. MJA. 2008;188(8):464-8.

17. Narantuya D. Will Mongolian Doctors Leave Poland? Migration World Magazine. 1999;27(1):24-6.

18. McGrath PB. Integration of overseas-trained doctors into the Australian medical workforce. MJA. 2004;181(11/12):640-2.

19. Fiscella K, Frankel R. Overcoming cultural barriers: international medical graduates in the United States. JAMA. 2000;283:1751.

20. Birrell JR. The regulation of Medical Practice in Australia, Canada, United States and Britain. . People and Place. 2004;40(12/3):40-51.

21. Korcok M. At least 12 US states refuse to recgnize physician training accredited in Canada. CMAJ. 1998;158(8):1061-3.

22. Allen I. Doctors crossing borders: Europe's new reality.
CMAJ. 2009;180(2):158-61.

23. CPMEC-NZ. Workshop on Education and Training for Permanent Resident Overseas Trained Doctors. Wellington: The Confederation of Postgraduate Medical Education Councils.2003.

24. CPMEC. Information and Resources relating to Education and Training available to Overseas Trained Doctors in Australia: A National Scoping Study.: The Confederation of Postgraduate Medical Education Councils.2004.

25. Audas R, Ross A, Vardy D. The Role of International Medical Graduates in the Provision of Physician services in Atlantic Canada: a discussion paper.2004 [cited 2006 Sept 11]: Available from: http:// www.mun.ca/harriscentre/IMG-Atlantic_MetropolisFINAL.pdf.

26. Eysenbach G, editor. Medicine and Medical Education in Europe- The Eurodoctor. New York: Thieme; 1998.

27. Romem Y, Benor DE. Training immigrant doctors: issues and responses. Medical Education. 1993;27(1):74-82.

28. Von Rosen J. Living and working in Sweden. BMJ Career Focus. 2003;326 (7399)(S 173).

29. Easton G. Warning all junior overseas doctors. 2005 [cited 2008 July 2]: Available from: http:// careers.bmj.com/careers/advice/viewarticle.html?id=661.

30. Sladden J. Overseas doctors' health. BMJ Career Focus. 2006;332(8).

31. Reid A. To Discipline or Not to Discipline? Managing Poorly Performing Doctors. In: Freckelton RI, editor. Regulating Health Practitioners. Annandale, Sydney.: The Federation Press.; 2005. p. 90-120.

32. Williams R. Ockham's Razor: Overseas trained doctors. Interviewing Prof Max Kamien on history of 'Overseastrained Medical Doctors at the post World War period (1915-1960) [serial on the Internet]. 2007 [cited 2017 Jan 31]: Available from: http://www.abc.net.au/rn/ ockhamsrazor/stories/2007/2051103.htm.

33. Wilkinson D. Inequitable Distribution of General Practitioners in Australia: Analysis by State and Territory using Census data. . AJRH. 2000;8:87-93.

34. AMA. Australian Medical Association: Review of Health workforce 2005 [cited 2009 July 16]: Available from: $h$ ttp://www.ama.com.au/node/3955.

35. Kidd MR. Hoops and Hurdles: towards a fairer recognition process for overseas trained doctors Sydney: University of Sydney 1999.

36. AMC. Handbook of Multiple Choice Questions 1st ed. Kingston, ACT: Australian Medical Council Limited.; 2009.

Bangladesh Journal of Medical Education 2018;9(1):26-34. 
37. RACGP. IMGs' specialist qualification recognition \& assessment. Royal Australian College of General Practitioners online [cited 2017 Jan 29]; Available from: http://www.racgp.org.au/becomingagp/imgaus/special ist-pathway.

38. AHPRA. Registration process for Overseaspractitioners. Australian Health Practitioner Regulation Agency online [cited 2017 Jan 24]; Available from: http://www.ahpra.gov.au/Registration/RegistrationProcess/Overseas-Practitioners.aspx.

39. Packwood MV, Packwood TW. Admission Requirements for International Students at Colleges and Universities in the United States. USA: Two Trees Press; 1986.

40. Bochner S, Wicks P. Overseas students in Australia. 1st ed. Randwick, NSW: New South Wales University Press; 1972.

41. Harden MR. What is an OSCE? Medical Teacher. 1988;10(1):19-22.

42. AMC. AMC Handbook of Clinical Assessment. Barton, ACT: Australian Medical Council Inc; 2007.

43. Murtagh J. MURTAGH' general practice. 4th ed. North Ryde, Sydney: The McGraw-Hill Australia; 2007.

44. Tjandra JJ, Clunie JAG, Kaye HA, Smith AJ. Textbook of Surgery. 3rd ed. Oxford, UK: Blackwell Publishing Pty Ltd; 2006.

45. Silverman J. Clinical communication training in continuing medical education: Possible, do-able and done? . Patient Education and Counselling. 2011;84:141-2.

46. Silverman J, Kurtz S, Draper J. Skills for communicating with patients. Oxford, UK: Radcliffe Publishing; 2005.

47. Stewart M, Brown JB, Donner A, McWhinney IR, Oates $\mathrm{J}$, Weston WW, et al. The impact of patient-centered care on outcomes. Journal of Family Practice. 2000;49(9):796-804.

48. Lillis S, St George I, Upsdell R. Perceptions of migrant doctors joining the New Zealand medical workforce. NZMJ. 2006;119(1229):1-9.

49. AMC. Anthology of Medical Conditions. Barton, ACT: Australian Medical Council Inc; 2003.
50. AMC.Annotated Multiple Choice Questions. Reprinted ed. Stafford BC, QLD: Blackwell Publishing Asia Pty Ltd; 2008 .

51. AMC. Notice against reproduction (recall) of exam materials. online [cited 2008 Oct 16]; Available from: http://www.amc.org.au/images/FormsMcqExam/Notic eforRecallQuests.pdf.

52. RACGP. Pre-employment structured clinical interviewPESCI. online [cited 2017 Jan 24]; Available from: http://www.racgp.org.au/becomingagp/imgaus/pesci/.

53. DIMBP. Migration of Medical Practitioners under the General Skilled Migration Program. Australian Government Department of Immigration and Border Protection; online [cited 2017 Jan 30]; Available from: https://www.border.gov.au/Trav/Work/Work/Allocatio n-dates-for-General-Skilled-Migration-applications/ migration-medical.

54. MBA. Competent Authority (CA) pathway for IMGs' accreditation. Medical Board of Australia online [cited 2017 Jan 30]; Available from: http://www. medicalboard.gov.au/Registration/InternationalMedical-Graduates / Competent-AuthorityPathway.aspx

55. AMC. List of accredited medical schools in Australia and New Zealand. Australian Medical Council online [cited 2017 Jan 30]; Available from: http://www. amc.org.au/accreditation/primary-medical-education/ schools.

56. AMC. Search tool to identify eligible medical schools for the AMC assessment on primary-medical-degree. Australian Medical Council online [cited 2017 Jan 30]; Available from: http://www.amc.org.au/assessment/ list-of-medical-schools.

57. Nair RB, Alexander GH, McGrath PB, Parvathy SM, Kilsby CE, Wenzel J, et al. The mini clinical evaluation exercise (mini-CEX) for assessing clinical performance of international medical graduates. MJA. 2008;189(3):159-61.

58. Douglas S. Listen to IMGs and reform the system. Overseas trained doctor [serial on the Internet]. 2009 [cited 2009 Sept 7th]: Available from: www.medicalobserver.com.au/otd/OTD_July_09.pdf.

Bangladesh Journal of Medical Education 2018;9(1):26-34. 